\title{
CENTRALISMO, CORRUPÇÃO E CULTURA DO JEITO NA REPÚBLICA FEDERATIVA DO BRASIL
}

http://dx.doi.org/10.21527/2176-6622.2018.50.152-163

Recebido em: 3/11/2017

Aceito em: 22/10/2018

Aristides Cimadon

Graduação em Filosofia (1974) e Pedagogia (1976) pela Universidade de Passo Fundo. Bacharelado em Direito pela Universidade do Oeste de Santa Catarina (1995). Mestrado em Educação pela PUC-RS (1982) e em Direito pela UFSC (1998). Doutorado em Ciência Jurídica pela Universidade do Vale do Itajaí (2006). Foi coordenador do processo de criação da Universidade do Oeste de Santa Catarina (Unoesc) e seu primeiro reitor. Atualmente é reitor reeleito para a gestão 20162020 e professor titular da Unoesc. Conselheiro do Conselho Estadual de Educação (1988-1999), reconduzido em março de 2011 para um mandato de seis anos (até fevereiro de 2017). Foi vice-presidente (2012 a 2014) e presidente da Acafe (2014 a 2016). Foi membro do Conselho para o Desenvolvimento do Estado de Santa Catarina - Desenvesc. Foi presidente da Fundação Cetepi (2013 a 2015). É membro da Academia Catarinense de Letras Jurídicas, Cadeira no 35. Tem experiência na área de Educação, com ênfase em Métodos e Técnicas de Ensino, Orientação Educacional e Teorias da Aprendizagem. Advogado, foi procurador jurídico da Fundação mantenedora da

Unoesc. aristides.cimadon@unoesc.edu.br

\section{RESUMO}

O presente artigo discorre sobre o aviltamento dos princípios do federalismo, cuja maioria de competências do Estado se centraliza na União. Apresenta argumentos a respeito da ilusão da Democracia, da participação popular e alerta para a formação de uma consciência forjada pelos meios de comunicação e pela retórica de marketing. Procura demonstrar que o federalismo brasileiro não cumpre o princípio da autonomia de competência do Estado Federado. Traz argumentos sobre a ilusão da Democracia, da participação popular e alerta para a formação de uma consciência manipulada pelos meios de comunicação e pela retórica de marketing. Enfim, procura demonstrar que o federalismo brasileiro não cumpre o princípio de autonomia de competência do Estado Federado.

Palavras-chave: Estado Federal. República. Centralismo. Corrupção.

\section{CENTRALISM, CORRUPTION AND CULTURE OF CHEATING IN THE BRAZILIAN FEDERATIVE REPUBLIC}

\section{ABSTRACT}

This article discusses the debasement of the principles of federalism, whose majority of state powers are centralized in the Union. It presents arguments about the illusion of Democracy, of popular participation and alert to the formation of an awareness forged by the media and marketing rhetoric. Finally, it seeks to demonstrate that Brazilian federalism does not comply with the principle of autonomy of competence of the State. It presents arguments about the illusion of Democracy, of popular participation and alert to the formation of a conscience forged by the media and Marketing rhetoric. Finally, it seeks to demonstrate that Brazilian federalism does not comply with the principle of autonomy of competence of the State.

Keywords: Federal State. Republic. Centralism. Corruption.

\section{SUMÁRIO}

1 Considerações iniciais. 2 Aspectos históricos do federalismo brasileiro. 3 O federalismo na Constituição de 1988. 4 A corrupção, o falseamento do princípio da legalidade, da democracia e a cultura do jeito na República Federativa do Brasil. 5 Considerações conclusivas. 6 Referências. 


\section{CONSIDERAÇÕES INICIAIS}

Evidentemente há diferença considerável entre o que se entende por Estado Federado e Confederação de Estado. Nesse sentido, Lapergola (1994) revisa o federalismo como processo com fundamento na teoria de Carl Friedrich, e mostra que a base harmônica estrutural do Estado Federal reside, especificamente, na distribuição de competências e autonomia entre os Entes Federados e a União. $\mathrm{O}$ autor afirma:

[...] la autonomía constituye un nivel intermedio entre aquellos que se encuentran en las fronteras del auténtico federalismo; autonomía, no sería, en suma, soberanía, y al propio tiempo significaría una cosa muy diversa y superior del reconocimiento en cada uno de los cuerpos locales de atribuciones no garantizadas constitucionalmente (LAPERGOLA, 1994, p. 60). ${ }^{1}$

O Estado brasileiro adota, no que diz respeito à instituição do Poder e à relação entre governantes e governados, a forma de governo Republicana, constituída, na sua organização político-administrativa, em um formato de Estado Federal. Em sua funcionalidade jurídica e administrativa, todavia, constitui-se como um Estado Unitário. O problema da autonomia dos Entes Federados está no centro do pacto federativo. É sobre esses aspectos que se discorre adiante, procurando mostrar como a rapinagem, a razão ornamental, o conformismo e a servidão voluntária (GOMES, 1979) na República brasileira, falseiam a Democracia, promovem a cultura de rapina e da 囦azão do jeito?? não permitindo a existência de um federalismo autêntico. A corrupção transformou-se num dos principais males da República, e suas raízes ameaçam a Democracia e promovem a insegurança jurídica. Não há, pois, como entender o termo República sem considerá-lo que esteja intrinsecamente ligado à Democracia e à Ética.

O ser humano, para Arendt (2001), é eminentemente um ser social, porque não pode viver sem convivência, e esta pressupõe normas, regras e valores. Por esse fato, sua sobrevivência depende da vida organizada. O homem é, portanto, por natureza, político. Sua condição humana depende da organização da vida feita em duas esferas: a pública e a privada. Assim, o homem constituiu, ao longo da história, diferenciadas formas de organização, tendo nelas as normas reguladoras que disciplinam a boa convivência. $\mathrm{O}$ aparato da estrutura normativa determina uma hierarquia cujo valor do privado é entendido como particular, pessoal, ou de grupos, e o público como bem comum pertencente a todos os cidadãos de determinado território. Ora, o Estado republicano tem por essência uma organização política com privilégio do público gerido pelo povo que elege seus representantes, com o objetivo de criar condições favoráveis à existência de qualidade de vida e paz social.

A compreensão milenar de Estado, em Platão (2001), ${ }^{2}$ faz entender que é uma Instituição Política que deve estar acima dos interesses particulares, e sua finalidade suprema é providenciar o bem coletivo mediante a educação espiritual e intelectual do ser humano. A organização do Estado, portanto, implica uma sólida estrutura jurídica. O Estado ideal de Platão se vale de dois instrumentos fundamentais para o homem: a Educação e o Direito. Este deve ser entendido como a compreensão da lei, escrita ou não. A lei é uma necessidade para a organização da cidade justa. Um Estado não pode existir sem leis. Como ele tem a finalidade da promoção da justiça, esta somente será realidade à medida que as leis são cumpridas.

Para Aristóteles (1999), todavia, o Estado é uma instituição política que nasce da natureza social do homem, ou seja, é a sociedade juridicamente organizada. A sua função fundamental é a educação dos cidadãos e não a força, a guerra e a conquista. O Estado é um organismo moral, condição e complemento da atividade moral e do bem comum. Ele compreendia a educação como causa da felicidade e a maneira de preparar o cidadão para a vida em Sociedade, ensinando a praticar a Justiça. Esta é considerada por Aristóteles a excelência moral perfeita e, portanto, uma virtude fundamental para a vida social, pois é a única que se relaciona com o próximo e com o bem do indivíduo. É, portanto, uma predisposição do caráter forjado pela educação.

\footnotetext{
${ }^{1}$ A autonomia constitui-se num nível intermediário entre aqueles que se encontram nas fronteiras do autêntico federalismo; autonomia não seria, em suma, soberania, e ao mesmo tempo significaria uma coisa muito diversa e superior do reconhecimento em cada um dos corpos locais de atribuições não garantidas constitucionalmente.

${ }^{2}$ Evidente que à época Platão compreendeu a organização do Estado com objetivo principal reservado às classes superiores, desinteressandose do povo trabalhador, cuja função é o tarefismo e a obediência. Não é essa a compreensão da função social do Estado.
} 
La justice contient toutes les autres vertus. Elle est une vertu absolument complète parce que sa pratique est celle de la vertu accomplie. [...] L'homme qui exerce une charge publique, en effet, est immédiatement en rapport avec autrui et participe à la communauté civile. Cette rason même fait que, seule de toutes les vertus, la justice parait être un bien que ne nous est pas personnel, puis-qu'elle intéresse les autres (ARISTOTE, 1999, p. 119-201). ${ }^{3}$

Tanto Platão quanto Aristóteles não fazem menção aos direitos individuais civis ou sociais, como estão hoje dispostos na Constituição da República Federativa do Brasil de 1988, mas apregoam que tudo, na organização do Estado, deve girar em torno do coletivo, isto é, de todas as pessoas. Dos ensinamentos dos estudiosos citados entende-se que o Estado deve ser a organização político-administrativa de proteção territorial do cidadão.

O Estado moderno, de acordo com Dallari (1987), entretanto, é um ente jurídico produto da sociedade e, por assim ser, exige forma de organização e regime de governo permeado pela Democracia. A organização política do Estado, também proposta por Montesquieu (2000), exige a forma Republicana que tem, em sua essência, a Repartição de Poderes e a escolha dos governantes e cargos políticos preenchidos periodicamente, independentemente do regime de governo.

O Estado contemporâneo, na concepção de Pasold (2003), é um complexo político, cujos ordenamentos jurídicos clarificam os grandes objetivos dirigidos ao bem comum ou ao interesse coletivo, isto é, há uma evidente e essencial função social do Estado. Se constituído como República, na forma Federal, tem que, necessariamente, vivenciar os princípios da Democracia, da Repartição dos Poderes e da descentralização. A Democracia, por exemplo, não pode se transformar em aliança de oligarquias, de conluios ou alianças que falseiam os partidos políticos, formando partidos subjacentes organizados por questão de conveniências e interesses de grupos econômicos.

\section{ASPECTOS HISTÓRICOS DO FEDERALISMO BRASILEIRO}

A organização político-administrativa do Brasil ocorreu de forma, aparentemente, descentralizada (ClMADON, 2007, 2008). Essa descentralização não se concretizou na prática da vida política nacional. Portugal, em 1543, com o objetivo de ocupação e colonização das novas terras, considerando a grande expansão territorial brasileira, separou o território em 17 capitanias hereditárias. Esse sistema havia funcionado bem em Açores e na llha da Madeira. Portugal, preocupado com a pirataria, contrabando de pau-brasil e outros problemas da colonização, dividiu a Colônia em porções de terra e as doou a homens "ilustres" e amigos da Coroa.

Conforme escreve Valuce (1973), a estes homens foram dadas atribuições de colonizar o Brasil, as suas próprias expensas, com poderes para escravizar índios e vendê-los, fundar povoações, comprar escravos, nomear funcionários, doar sesmarias, julgar e condenar, inclusive à morte, escravos e homens livres, estabelecer impostos e receber parte daqueles cobrados pela Coroa.

O sistema, contudo, não obteve sucesso, fazendo com que, em 1548 fosse criado um Governo Geral. Em 1573 o Brasil foi dividido em dois governos, um com sede em Salvador e outro no Rio de Janeiro, voltando à forma anterior. Em 1580, Portugal passa ao domínio espanhol, mas permanece a mesma orientação administrativa. O longo período histórico do Brasil colônia é marcado por algumas características descentralizadoras com certas autonomias dadas às províncias ou capitanias hereditárias. Teixeira da Silva (1990, p. 57) escreve:

As capitanias, imensos espaços de terra, foram distribuídas entre fidalgos da pequena nobreza, já que os grandes se interessavam mais pelas Índias ou por ter terras no Reino e suas ilhas adjacentes. Em geral, os donativos eram feitos por ordem de Dom Manuel, a funcionários da burocracia monárquica com estreitas ligações com cristãos novos, judeus recém convertidos. Nesse sentido há um sentimento de independência ou autonomia de gestão das terras recebidas. O Estado português tinha como um de seus objetivos a ocupação do território brasileiro, demarcado várias vezes.

\footnotetext{
${ }^{3}$ Tradução por Jean Voilquin. A justiça contém todas as demais virtudes. Ela é uma virtude absolutamente completa porque sua prática é aquela da realização da virtude por excelência. [...] O homem que exerce um cargo público, com efeito, está diretamente relacionado com o outro e participa da vida comunitária. Por esta razão, faz com que, dentre todas as virtudes, a prática da justiça parece ser um bem que não é puramente pessoal, mas é interesse da coletividade.
} 
De acordo com Zancanaro (1994), as metas do Estado português estão fundadas na ação absolutista, privativista e centralizadora do Reino, cujo modelo jurídico arbitrário e casuístico apresenta uma burocracia de exacerbadas atribuições funcionais e uma Ética predatória e de rapinagem. As relações e a cultura de produção anárquica fazem parte do cotidiano, com aversão ao trabalho e mania nobiliária ou, em outros termos, cultivo da razão ornamental. A fragilidade da ordem jurídica e o espírito nômade e de improviso da cultura do Estado português, foram transportados para o Brasil, com acréscimo de desenfreada e requintada corrupção político-administrativa. Em 1808, Dom João VI vem ao Brasil compelido por Napoleão Bonaparte, instalando-se no Rio de Janeiro, enraizando, de vez, a organização confusa da administração portuguesa. Em 1815, o Brasil foi elevado a Reino Unido de Portugal e, em 1822, torna-se Império, como Estado independente e soberano, cuja estrutura político-administrativa fora estabelecida na Constituição de 1824.

A Carta Imperial de 1824 privilegia a centralização político-administrativa, insiste na forma unitária de Estado, bem como divide o território brasileiro em 20 províncias subordinadas ao poder central e dirigidas por presidentes escolhidos e nomeados pelo Imperador. A Constituição do Império mantém, em princípio, a estrutura das Províncias, sua divisão territorial (artigo 2ㅇ) e garante a rigidez constitucional (artigo 15, VIII).

De acordo com o que relata Zancanaro (1994), entre 1831 e 1837 os regentes chegaram a conceder maior liberdade para as províncias; entretanto, a partir da regência de Araújo de Lima, inicia-se um processo de maior centralização política e, consequentemente, o governo retira a liberdade concedida. Aprofundam-se as características da burocratização, o caráter casuístico das leis, a impunidade dos delitos e cresce o estímulo à corrupção. Como se pode inferir, essas características permaneceram, aperfeiçoando-se ao longo da história do Brasil e se aprofundando com requintes de tecnologia nos dias atuais.

Ferreira de Melo (1989) relata que, embora o Brasil não tivesse formado uma Federação pela reunião de Estados soberanos, sempre houve uma vocação federalista, uma vez que a organização política brasileira, desde as "antigas províncias coloniais, oriundas de entidades quase autárquicas, que foram as capitanias, tinham um sentimento autonômico" e moldaram as províncias imperiais. Essa vocação federalista traduziu-se na Constituição de 1824, mas não observou os princípios da descentralização e da Autonomia do Estado Federado, instituindo uma forma unitária de organização político-administrativa. A efetivação das Províncias, como Entes Federados, com certa descentralização política, não atendeu os sentimentos autonomistas que foram crescendo durante o Brasil Império, culminando com a consolidação da República e a adoção constitucional do modelo federativo.

O Brasil, portanto, constitui-se em uma República e Estado Federal a partir da Constituição de 1891. Embora República Federativa, a cultura centralista e o desrespeito pela norma Constitucional permanecem, como uma herança que colou em todos os níveis de governo brasileiro. Ruy Barbosa (2009), em seus diversos discursos a respeito da organização da República, mostra que a soberania do país é do povo. Nem sempre, contudo, o povo, por intermédio de eleições, muda os governos. Infelizmente o povo parece perpetuar os corruptos e pouco agir contra a corrupção, tampouco é a República que faz mudar o governo e disseminar a justiça. Na essência do Estado Republicano, portanto, estão os princípios da Soberania, da Repartição dos Poderes, da Democracia e do Direito, mas a história da vida política e social brasileira mostra que esses princípios sempre foram vilipendiados.

\section{O FEDERALISMO NA CONSTITUIÇÃO DE 1988}

A história do Brasil mostra que houve alternância, quase sistêmica, entre autoritarismo e Democracia. Em consequência, criou-se uma cultura de Estado Unitário. A Constituição de 1988, todavia, distribui maior descentralização de competências dentre todas as Constituições brasileiras e reorganiza o federalismo. $\mathrm{O}$ artigo 10 da Constituição da República Federativa do Brasil de 1988 estabelece que o Brasil é uma República Federativa, formada pela união dos Estados e Municípios e do Distrito Federal, constituindo-se num Estado Democrático de Direito. $O$ citado artigo estabelece, ainda, os fundamentos da sua organização. ${ }^{4}$

\footnotetext{
${ }^{4}$ Art. 1ㅇ A República Federativa do Brasil, formada pela união indissolúvel dos Estados e municípios e do Distrito Federal, constitui-se em Estado Democrático de Direito e tem como fundamentos: I - a soberania; II - a cidadania; III - a dignidade da pessoa humana; IV - os valores sociais do trabalho e da livre iniciativa; V - o pluralismo político (BRASIL, 1988).
} 
Assim, a Constituição de 1988, artigos 21 a 30, estabelece diversas autonomias que se constituem deveres e direitos dos Entes Federados. A descentralização mais efetiva ocorre quando se refere às competências comuns, mais especificamente quando o artigo 24 estabelece as competências legislativas concorrentes. Define, também, em seu artigo 5ㅇ, uma série de direitos fundamentais individuais e, em seus artigos 60 e seguintes, os direitos fundamentais sociais, como também os requisitos de nacionalidade (artigo 12) e os direitos políticos (artigo 14).

Não há dúvida que, na perspectiva da Constituição de 1988, surgiram "novos" direitos e formas outras de sua proteção. As ações do Poder Executivo, porém, não têm garantido esses direitos que são acrescidos, cotidianamente, por leis esparsas do Legislativo, que as aprova com objetivos eleitoreiros. Os cidadãos, nesse entulho legislativo contraditório e antinômico, buscam a proteção no Judiciário. Verifica-se o crescimento e a judicialização dos problemas, como esperança de garantia dos direitos, que também são pouco amparados, com inúmeras decisões judiciais contestadas pela opinião pública e pelos estudiosos do Direito, aumentando a insegurança jurídica.

Sem embargo, apesar de certa descentralização, a União reservou para si a maior parte de competências e centralizou a arrecadação de tributos, organizando uma perversa forma de distribuição dos recursos, principalmente mediante emendas parlamentares e regulações sobre contratações. Esse procedimento "legal", incluindo os processos de licitação e compras, incentivam a rapina e a corrupção. Em consequência, instalou-se a corrida dos governantes e dirigentes institucionais com "chapéu na mão", como se pedissem esmolas para atender compromissos derivados da autonomia. Instituiu-se um sistema de representação política que permitiu coligações espúrias, forçando a que os Partidos Políticos abdicassem de ideologias, para aniquilarem-se ante os "partidos subjacentes", organizados com fins econômicos e interesses particulares.

São muito atuais as observações de Ruy Barbosa que denunciam o sempre aviltante desrespeito aos princípios fundamentais da Constituição. Ele postulou o fiel cumprimento dos princípios da repartição dos poderes, da Democracia e da legalidade, contra desvios políticos da ordem constitucional, mormente atentatório ao sistema federativo. Constatou uma forte tendência centralizadora da parte do executivo federal, bem como sua propensão autoritária de estabelecer um controle político sobre os Estados-membros e sobre os demais poderes, mormente sobre o Poder Judiciário.

Eu era federalista antes de ser republicano. Não me fiz republicano senão quando a evidência irrefragável dos acontecimentos me convenceu de que a monarquia se incrustara irredutivelmente na resistência à federação (BARBOSA, 2009).

Por outro lado, os Estados e os municípios, dependentes de liberação financeira da União, conformam-se e deixam de exercer a autonomia de competências em diversas áreas, sobretudo nas questões do Direito Ambiental e Educacional. Como consequência da centralização, acelera-se uma prática paternalista que alimenta atitudes passivas das massas e até mesmo o silêncio dos mais esclarecidos. Tudo isso é reforçado pela ausência de planejamento de Estado que cede lugar à instituição de políticas de governo com interesses particulares. A Democracia é falseada e a opinião pública fabricada pelos meios de comunicação, que manipulam as informações em troca de contratos com altos recursos financeiros.

Por outro lado, observa-se, nas camadas mais pobres, e até entre a população mais escolarizada, a ilusão da participação democrática. De acordo com Zancanaro (1994), as práticas políticas no Brasil, ainda sob os resquícios da época colonial, privam a Sociedade brasileira de desenvolvimento de padrões sociais éticos. Além disso, induzem a confundir o público com o privado e a conceber a ordem jurídica como um recurso a ser manipulado em favor próprio, alimentando a corrupção em todos os níveis de governo, nutrindo a impunidade tanto dos corruptos quanto dos corruptores.

De acordo com o STF, há um dever de obediência ao subprincípio da simetria ${ }^{5}$ constitucional. Se assim for, Lamy (2009) mostra que não há supremacia de poder de um Ente Federado sobre outro. Em outras palavras, os Entes Federados não apresentam entre si qualquer relação de hierarquia. Os Entes Federados

\footnotetext{
Simetria, como princípio dinâmico do federalismo, ou subprincípio, significa a obrigatoriedade de as unidades parciais do Estado Federal observarem um determinado modelo ou um padrão na sua organização e no exercício da autonomia do poder local. É a harmonia resultante de autonomias proporcionais.
} 
devem possuir, portanto, autonomia, isto é, atribuições entendidas como capacidades jurídico-constitucionais de auto-organização (artigo 25, caput), autolegislação (artigo 25, caput), autoadministração (artigo 25, §10) e autogoverno (artigos 27, 28 e 121 da CF/88), sem que cada membro seja obrigado a consultar a vontade dos outros para decidir a respeito da solução dos problemas locais, desde que respeitadas suas competências.

Segundo Martins (2003, p. 120), a simetria é "um dos mais polêmicos sub-princípios dinâmicos do princípio federativo", porque trata de descentralização política constitucional, atuando, sobretudo, sobre a capacidade de auto-organização dos membros federais, significando a obrigatoriedade de observarem determinado modelo ou padrão na organização e no exercício do poder local. O raciocínio pode ser assim resumido: se determinada situação não foi prevista para a União, não podem os Estados federados estabelecê-la.

Conclui-se, portanto, que o Federalismo Brasileiro, embora apresente, na sua organização político-administrativa, os fundamentos gerais que sustentam as características de descentralização do Estado Federal, assemelha-se, entretanto, aos federalismos assimétricos ou de simetria negativa. A assimetria é uma anomalia violadora da autonomia de competências dos membros da Federação, porque não se percebe harmonia de distribuição de competências. A Constituição de 1988 parece ter corrigido, em parte, essa anomalia, mas, na prática, não se configura a simetria, uma vez que a União detém o maior contingente de competências e, não raramente, invade a autonomia dos Estados e dos Municípios (CIMADON, 2007, p. 345).

A Constituição brasileira de 1988, denominada de "Constituição Cidadã", possui em seu arcabouço inúmeras qualidades garantistas, mas traz uma organização político-administrativa com perversa distribuição de competências entre os Entes Federados, sobretudo, em relação aos tributos. Ela permite uma organização partidária que falseia a Democracia e a existência de Partidos Políticos autênticos, construindo uma prática redistributiva de recursos com requintes extraordinários de corrupção. A atual conjuntura política do Brasil está pressionando para urgente revisão do pacto federativo brasileiro, com necessidade, na essência, de reformas significativas do campo político, tributário, estrutural e administrativo, inclusive na forma da composição das cortes supremas do Poder Judiciário, de competência e autonomia dos Estados-membros.

A Constituição da República Federativa do Brasil de 1988, portanto, apesar de ter alargado a autonomia de competências, criando, inclusive, o município como Ente Federado autônomo, por seu centralismo tributário, falseia a verdadeira autonomia, porque torna os Entes Federados dependentes da União.

\section{A CORRUPÇÃO, O FALSEAMENTO DO PRINCÍPIO DA LEGALIDADE E DA DEMOCRACIA E A CULTURA DO JEITO NA REPÚBLICA FEDERATIVA DO BRASIL}

O conceito de República é, de certo modo, ambíguo, porque se confunde com Democracia e, às vezes, com liberalismo. Sua compreensão relaciona-se, todavia, com o "bem comum" e o "respeito às instituições". A Democracia é essencial à República, uma vez que ela se contrapõe aos regimes autoritários. Conforme Celso Lafer $(2009$, p. 6), República vem do latim - res=coisa + publica = comum a todos. Literalmente, é um regime de governo que privilegia o bem público, isto é, a coisa pública ou comum. Assim, um Estado republicano não pode prescindir da Democracia. Foi Cícero (1995) quem examinou a especificidade do conceito de República, ao diferenciar res publica de outras, como a res privata, a domestica, a familiaris, estabelecendo, dessa maneira, uma distinção entre o público, isto é, o comum, que corresponde, no grego antigo, às formas substanciadas do adjetivo koinós (comum, público) e, modernamente, à expressão italiana il comune, e o privado, que não é comum a todos, mas, particular a alguns.

Para Maurício Mesurini da Costa (2009, p. 9), o elemento central do regime republicano é a "visibilidade". Reportando-se a Bobbio, o autor mostra que o Estado é do povo e, portanto, o governo deve ser transparente no sentido de que seus projetos e aplicação de recursos estejam visíveis aos cidadãos, embora existam ações sigilosas com o objetivo de resguardar os direitos fundamentais. A Constituição brasileira de 1988, em seu artigo 37, caput, consagra os princípios de legalidade, impessoalidade, moralidade, publicidade e eficiência como essenciais à gestão pública. Continuamente, os governos republicanos que foram se sucedendo confundiram o público com o privado. A impressão que se tem é que o Estado brasileiro tem "donos" que fazem dele um bem próprio ou exclusivo de grupos. 
O patrimonialismo ${ }^{6}$ está enraizado na administração pública brasileira, redundando na degeneração da coisa pública em coisa privada. Daí o desrespeito da população pelas coisas públicas, agindo com e sobre elas, como se não fossem suas. O Estado não é entendido como propriedade do cidadão, mas um Ente comum sobre o qual não há necessidade de cuidado. Dessa falta de cuidado advêm consequências, como a depredação da coisa pública, a despreocupação do cidadão com o controle das atividades de governo, e outros tantos desinteresses. Historicamente, essa consciência conduz à falta de visibilidade, aumento da corrupção, irreverência aos princípios da legalidade e da impessoalidade, essenciais do modelo republicano.

O fenômeno da corrupção, todavia, não é apenas um problema brasileiro. Ele parece estar enraizado na cultura latina. Estudos de Woff (1998) ${ }^{7}$ mostram práticas de corrupção na América Latina que vêm destruindo a decência, a ética e a confiança nos negócios e nas relações sociais. A "corrupciocracia" (FERNANDES, 2000) ${ }^{8}$ nas Repúblicas Latino-americanas, sobretudo no Brasil, tem se mostrado cada vez mais escancarada. Woff (1998) relata, inicialmente, que, diferentemente do que aconteceu na América Latina, a corrupção na Alemanha e na Europa, em geral, nunca foi uma manifestação saliente da vida social e política. As tradições morais e educacionais mais rigorosas sempre conseguiram impedir que ela tomasse pé no governo, no parlamento, na administração pública, no Judiciário, ou que pudesse se transformar em uma estrutura latente ao poder público, muito embora, nos últimos tempos, tenha aumentado a estatística de casos de corrupção. Conforme relata Woff (1998):

Para os latino-americanos a corrupção integra a lógica do quotidiano. Ela é estrutura social, norma de comportamento, forma de consciência porque "não há vida sem mordida". Diz-se no México e no Paraguai: "também quem não aceita coima é corrupto, porque precisa pagá-la". A corrupção sempre reclama a sua parte, reza a experiência venezuelana: "Todos querem sua tajada, de policiais aos ministros, dos empregados ao patrão". E no Brasil sabe-se que "sem propina nada anda e, portanto, a corruptolândia está em toda parte" (p. 413-432).

O caso da Venezuela é típico. ${ }^{9} \mathrm{Em}$ todos os contratos em que o Estado é parte corre dinheiro por fora. Quem quer fechar um contrato com o Estado precisa incluir uma comissão de $5 \%$ a $10 \%$ do seu valor, que será entregue a um "testa de ferro". Se fiscais vão a uma empresa para examinar seus livros, ou controlar o cumprimento das prescrições legais, uma comissão protege-a contra notificações ou multas até a próxima visita.

Conforme relata Woff (1998), na Argentina é costumeira a regra dos 10\% de propina nos negócios do setor público. Sem isso não se faz contrato com nenhum órgão de governo. Também, o desembaraço alfandegário, a elaboração de documentos, a instalação de telefone, licenças de construção e de importação dependem do pagamento de uma coima. Os subornos estão na base das empresas, principalmente, na construção civil. Alianças entre construtoras, prefeitos, repartições, cartórios, arquitetos e agentes financeiros dominam o lucrativo negócio da especulação.

O mesmo autor supracitado relata que a corrupção, na Colômbia, gira em torno de $20 \%$ dos investimentos públicos. As obras públicas, os sistemas de comunicação, as compras de armamento, movimentam juntas até $5 \%$ sobre o valor dos contratos. O Peru viveu, na presidência de Alan Garcia, uma época de "corrupção oficial", com a "regra de 8\% para o Ministro". O presidente não era a exceção. Quando a Marcel Dassault negociou um contrato para a venda de 24 aviões Mirage, afastou com regalos qualquer dúvida dos políticos e militares responsáveis pela decisão. $O$ escândalo, contudo, não residiu nisto: ninguém ficou sabendo a razão pela qual o país, envolvido na recessão e na dívida externa, veio a precisar de 24 Mirages do modelo mais recente: o presidente teve de negociar um novo contrato, que the rendeu de novo um regalito, diz Woff (1998).

\footnotetext{
${ }^{6}$ A categoria patrimonialismo significa um tipo de organização política em que há dependência econômica e um sentimento de obediência do governado. Compreende-se, também, que os governantes não devem ser questionados porque são figuras a serem reverenciadas, das quais se espera a solução dos problemas locais. A forma de governo, que deveria ser impessoal, se torna pessoal e até personalíssima.

7 Paul Woff é professor de Filosofia do direito em Frankfurt. Esse texto foi extraído do volume terceiro (Macrodelinqüência), organizado pelo professor Klaus Lüderssen e publicado por Nomos Verlagsgesselschaft, em Baden-Baden, 1998, com o título Aufgeklärte Kriminalpolitik oder Kampf Gegen das Bose? (Política Criminal Racional ou Luta contra o mal. p. 413-432).

${ }^{8}$ Categoria empregada por Newton Fernandes. A "corrupciocracia" brasileira e as formas utilizadas nas investigações criminais correlatas.

${ }^{9}$ Ver mais em Diccionario de la corrupción en Venezuela, vol. I, 1959-1979, Caracas, 1980; "El mapa de la corrupción en los negocios latinoamericanos"; Rev. América Economia (New York), año 4, n. 42, ago. 1990, p. 9-20; A era da corrupção, Veja (São Paulo), ano 27, n. 1, 5 de janeiro de 1994, p. 80-93.
} 
De acordo com os relatos de Wolffang Schaupeinsteiner, ${ }^{10}$ citado por Woff (1998), também os círculos oficiais brasileiros, em muitos casos, tiraram proveito pessoal da competição internacional por grandes encomendas. Em 1975, por exemplo, como parte de um acordo teuto-brasileiro, a agência atômica da Alemanha Ocidental arrematou uma encomenda em torno de 12 bilhões para usinas nucleares brasileiras. Isso rendeu algumas "pequenas" propinas e subornos. A corrupção, no Brasil, revela que o patrimonialismo está enraizado na cultura e na administração pública, em todos os Poderes.

Um breve histórico ${ }^{11}$ dos noticiários dos escândalos divulgados nos últimos 35 anos, guardadas algumas variáveis, com destaque para a Democracia e a liberdade de imprensa, observa o que segue: a) 1974 a 1979 no governo de Ernesto Geisel foram divulgados 8 casos de corrupção ou escândalos. O caso Herzog foi o mais comentado; b) 1979 a 1985 - no mandato do presidente João Batista Figueiredo, foram difundidos 10 casos, dentre os quais foram muito notados o crime da mala e o escândalo da mandioca; c) 1985 a 1990 - José Sarney teve 6 casos de escândalos divulgados, dentre os mais comentados está a CPI da corrupção. Nesse período, o Brasil atingiu índices de inflação de $84 \%$ ao mês, e o governo chegou a criar o Overnight para remunerar o aplicador; d) 1990 a 1992 - no governo de Fernando Collor foram divulgados 18 escândalos, sendo o mais crítico o "esquema de PC Farias". As acusações de corrupção o levaram ao impeachment; e) 1992 a 1995 - assumiu o governo o presidente Itamar Franco, que teve noticiados 31 escândalos, sendo o mais famoso aquele dos "anões do orçamento"; f) 1995 a 2003 - no governo de Fernando Henrique Cardoso foram descobertos 44 casos de escândalos de corrupção. O caso que mais chamou a atenção foi aquele dos precatórios; g) 2003 até hoje - no governo Luiz Inácio Lula da Silva, Dilma Rousseff e Michel Temer foram noticiados incontáveis casos de corrupção; dentre eles são destaque o da CPI das ONGs, dos cartões corporativos, das irregularidades do bolsa família, dos dólares na cueca, do mensalão, da carne fraca e o maior de todos: a Lava Jato.

A operação Lava Jato desvendou a corruptocracia brasileira no governo da União e incentivou muitas outras operações nos Estados e municípios, escancarando a prática do desvio do dinheiro público de modo a estarrecer a população brasileira mais letrada. A República "Tupiniquim", depois da Lava Jato, não será mais a mesma. Os números mostram que a corrupção, neste início de século, passou a ser um processo normal da ação de governo, com apoio dos três Poderes da República. Exemplo dessa prática está na delação premiada de Joesley Batista, da JBS Foods S.A.

De acordo com Alexandre Garcia (2017), dentre tantos desvios apontados pela Lava Jato, chama muita atenção aquele relatado pelo Tribunal de Contas da União sobre o empréstimo de 1 bilhão e 100 milhões de reais para a JBS comprar a National Beef, um grupo australiano denominado Tasman, e uma divisão da Smithfield Beef. O pedido de empréstimo foi no dia 11 de fevereiro de 2008. Em apenas 22 dias o projeto foi aprovado pelo governo Lula; um projeto que, em média, leva 200 dias, foi aprovado em menos de um mês. Diante da fenomenal rapidez, o Jornal O Globo pediu, com base na lei da transparência, a agenda dos presidentes do BNDS, quando foram descobertas reuniões "incríveis".

Por exemplo, do empréstimo de 1 bilhão e 100 milhões de reais, Joesley, três dias depois de ter pedido o empréstimo, visitou o presidente do Banco Nacional de Desenvolvimento (BNDS) às 14 horas e 54 minutos, no BNDS, e saiu às 17 horas e 7 minutos. Interessante é que, do projeto do empréstimo, uma das empresas não foi comprada pela JBS, mas a empresa não devolveu o dinheiro para a União. O Tribunal de Contas da União afirma que houve um prejuízo para as finanças públicas em torno de 711 milhões de reais. Conforme Alexandre Garcia, Joesley, do dia 10 de maio de 2007 até 16 de maio de 2016, foi 23 vezes ao gabinete do presidente do BNDS. O irmão dele fez 8 visitas em Brasília, mais 10 vezes no escritório da presidência do BNDS em São Paulo. Em 2006, a JBS faturava 4 bilhões e, em 2016, dez anos depois, faturava 170 bilhões de reais.

A corruptocracia, neste século, começou com Guido Mantega, na presidência do BNDS, quando saiu o primeiro financiamento internacional. Segundo Joesley, Guido Mantega acertou um recebimento de propina de 150 milhões de dólares, que iria para o Partido dos Trabalhadores (PT) no sentido de financiar as campa-

\footnotetext{
${ }^{10} \mathrm{Cf}$. Wolfang Schaupeinsteiner, diretor da repartição anticorrupção do Ministério Público em Frankfurt, in Der Spiegel n²2/1998, p. 18. Em relação ao negócio das grandes exportações da indústria nuclear alemã v. Der Spiegel n 20/1975 p. 60 e n² 24/1995 p. 34; também Darcy Ribeiro, Aos trancos e barrancos. Como o Brasil deu no que deu, Rio de Janeiro, 1985, n. 2.175.

${ }^{11}$ No site da Fundação Getúlio Vargas (FGV) é possível localizar um breve resumo dos escândalos de corrupção: <www.cpdoc.fgv.br/revista/ arq>.
} 
nhas de Lula e de Dilma. Segundo Joesley, o PT recebeu para as campanhas presidenciais em torno de 500 milhões de reais. Apenas de toda essa corrupção, Joesley, pela delação premiada, teve perdão judicial do procurador geral da República, confirmado e homologado pelo ministro relator da Lava Jato, Luiz Edson Faccin.

A corrupção está em toda parte, desde os mais simples escalões municipais aos altos postos de governo da União e em todos os Poderes. A operação "Lava Jato", entretanto, desencadeou um contorno de combate efetivo à corrupção, cujo resultado ainda parece improvável. Isso tudo leva a considerar as palavras de Ruy Barbosa, citado por Canton (2009), como altamente significativas no atual momento da história brasileira:

[...] Sinto vergonha de mim por ter feito parte de uma era que lutou pela Democracia, pela liberdade de ser e ter que entregar aos meus filhos, simples e abominavelmente, a derrota das virtudes pelos vícios, a ausência da sensatez no julgamento da verdade, a negligência com a família, célula mater da sociedade, a demasiada preocupação com o "eu" feliz a qualquer custo, buscando a tal "felicidade" em caminhos eivados de desrespeito para com o seu próximo (Ruy Barbosa).

Ainda, para reforçar o pensamento de Ruy Barbosa, convém citar Newton Fernandes (2000), quando discorre sobre a corrupção no Brasil:

\begin{abstract}
Brasil é um país que vive sob o jugo de um sem número de corruptos, de prevaricadores, de ignominiosos violadores do erário público, de fariseus da justiça e da verdade, de inimigos viscerais da Democracia responsável, de agressores do Direito, de desprovidos da ética e da razão, de "animais" de rapina; enfim, de uma malta de maus políticos, que, tal qual hienas ou chacais, lançam-se a devorar os últimos restos da carniça imoral e nauseabunda a que reduziram este nosso infeliz e pobre país, roendo-lhe, como abutres que são as sobras das carcaças esqueléticas de milhões e milhões de excluídos sociais, por eles condenados à morte por inanição" (p. 289-309).
\end{abstract}

A corrupção na República "Tupiniquim" (GOMES, 1979) é consequência de outro mal: a cultura do jeito. Aliado à razão do jeitinho e da forma de levar vantagem, encontra-se o conformismo, maneira própria de justificar a condição de pobreza, da miséria, da insolvência política, dos privilégios dos políticos e das autoridades do Poder Judiciário. Os que sofrem padecem resignados e aplaudindo os larápios como se suas maledicências fossem virtudes intelectuais. O homem sério, em nosso meio, é motivo de deboche.

A prática centralizadora de governo do Estado brasileiro conduz à razão do jeito e da consciência da servidão. A cultura do jeito até pode ser positiva, quando manifesta criatividade e inovação. É negativa, todavia, quando é fruto da burla, da falta de planejamento, da ausência da ordem e do cumprimento das regras. 0 jeito está a serviço da miséria e do conformismo: dá-se um jeito e burla-se a norma. Gomes (1979, p. 11) menciona que o conformismo ou a consciência da servidão encontra terreno fértil no Brasil. Justificar um comportamento, preferir a dependência, buscar privilégios, são comportamentos próprios da cultura nacional. Assim, o brasileiro aliena-se de dois modos: primeiro, rindo de si mesmo, acreditando que o Brasil é o país do futuro sem muito esforço e, portanto, tudo é tolerável; segundo, na ausência do poder crítico, que torna o sujeito autocomplacente e conformista.

É voz corrente que, diante dos problemas, dá-se um jeito em tudo, do existencial ao político, do físico ao metafísico, da norma jurídica ao Direito burlado. A essência da cultura do jeito é a não radicalização, que permite a indolência e a construção de um distanciamento entre a norma posta e a realidade de sua execução. Com o jeito estampa-se o espírito procrastinador de todo o ordenamento jurídico, isto é, a norma existe, mas seu cumprimento é mascarado. $O$ gosto pela eloquência, pelo discurso que ludibria a ação reflete a consciência do colonizado e do baixo nível de educação. O jeito, portanto, conduz ao conformismo, à manutenção do status quo, falseia o princípio da legalidade ${ }^{12}$ e a Democracia.

O artigo 5ㅇ, II, da Constituição da República Federativa do Brasil, prescreve: "ninguém será obrigado a fazer ou deixar de fazer alguma coisa senão em virtude de lei" (BRASIL, 1988). O discurso da normatividade aponta para as atribuições claras e harmônicas dos poderes, em que tudo está regulado por lei, isto é, as ações do poder estatal estão limitadas aos ditames do princípio da legalidade. Vê-se, pois, que somente a lei

\footnotetext{
${ }^{12}$ O princípio da legalidade significa a sujeição e a subordinação do comportamento às normas e prescrições editadas por meio do processo legislativo (COSTA; ALVES, 2003, p. 119).
} 
no sentido material e formal é a solução dos problemas sociais, limitando, assim, a liberdade e criando, apesar do ideário de uma sociedade livre, justa e solidária, diversas barbáries sociais sob o império das regras postas. Entre nós regula-se tudo. Então, há leis que "pegam" e outras que não "pegam". Não bastassem as leis, há uma parafernália de regras e regulamentos, decretos, portarias, instruções normativas. Uma pletora normativa que promove uma burocracia descomunal e ineficaz e que assola a realidade. Apesar disso, cresce a insegurança jurídica. Parece desfalecer a crença que o princípio da legalidade ordene a vida cotidiana e garanta a segurança e a paz.

Nesse particular, parece importante mencionar a contribuição de Atienza (1997), quando discorre a respeito da racionalidade legislativa. Para esse autor, há vários níveis de racionalidade legislativa, como a linguística, a jurídico-formal, a pragmática, a teleológica e a ética. A Lei, com todos seus aspectos de racionalidade, não pode ser considerada o único meio de solução dos problemas sociais. Para ele, a racionalidade ética é um instrumento imprescindível de fazer com que os Poderes tenham suas ações fundamentadas no princípio da legalidade, como maneira de cometer justiça e permitir que aqueles que governam ajam de modo tal que suas ações promovam o desenvolvimento.

Cabo Martin (2000) também corrobora essa posição, afirmando que a problemática da lei, nos últimos tempos, tem apresentado profundas mudanças que exigem novas reflexões. O problema organizacional e social do Estado tem levado a afirmar que a Lei está em crise. Com o advento da Constituição de 1988 concretizam-se novos conceitos e ideias jurídicas, permitindo que se alarguem as compreensões sobre Direito, legalidade, federalismo, soberania e Democracia, mas não só. Há também a possibilidade do entendimento de uma nova concepção de Estado que, no caso brasileiro, é Federal. Pela sua própria natureza, portanto, é descentralizado.

A Sociedade necessita de um Estado em que reine a Democracia participativa e a descentralização, a fim de que as instituições e as comunidades organizadas possam contribuir na solução dos problemas que, em sua maioria, são locais. Constata-se que os planos e as práticas de governo não garantiram os direitos fundamentais do cidadão. Em verdade, tornaram-se uma espécie de decepção da concretização das políticas públicas: nem a lei, nem os poderes do Estado são capazes de concretizar as grandes aspirações populares.

Lamy (2009) alerta, de modo categórico, que as práticas político-administrativas atuais, no Brasil, conduzem ao falseamento da Democracia, deterioram os valores da verdade, da ética e alimentam a corrupção. A falsa Democracia concretiza-se na prática política de mercado, em que o voto ou a eleição dos representantes do povo são resultados de barganha e negociação. Há uma opinião pública fabricada pela mídia e pelo marketing. Os meios de comunicação transformam homens sem caráter em heróis.

A comunicação de massa retira a consciência individual e coletiva, cuja manipulação fabrica opiniões e forma um tipo de consciência popular passiva e sem poder de reflexão para exercício das liberdades. $O$ rito da orientação cega é a do pensamento da maioria: quem não está com essa maioria está "fora da manada". Estar fora, nesse sentido, é ser rejeitado e, consequentemente, ter "diminuído seu poder no mundo da vida" (ARENDT, 2001). Há, pela mídia, pelos discursos, pela prática e ação do Direito e suas normas, uma desconstrução diária da participação coletiva na solução dos problemas e na busca de novos meios para a construção do desenvolvimento.

Não há como negar que a Constituição de 1988 alargou os instrumentos de Democracia e os remédios de sua preservação, bem como a garantia dos direitos individuais e sociais dos cidadãos e os mecanismos para protegê-los. Ainda impera, contudo, a cultura da prática centralista, da corrupção sem controle, das barganhas e dos conluios, dentre outras práticas políticas e administrativas acobertadas pelos meios de comunicação e pelos próprios Poderes. Aparentemente, a Constituição traz inúmeros direitos e poucos deveres.

\section{CONSIDERAÇÕES CONCLUSIVAS}

O federalismo brasileiro, apesar de todos os mecanismos de distribuição de competências, dos meios de participação popular e das garantias de direitos individuais e coletivos, apresenta progressiva degeneração moral. Conforme preleciona Abreu (2004), as causas do estiolamento administrativo e legislativo são visíveis na estrutura do poder político, no modelo e sistema eleitoral, no sistema tributário centralizador, na ordem constitucional de distribuição de competências, em que se vislumbra a invasão, por parte da União, na autonomia dos Estados Federados. 
Para o autor citado, "[...] é preciso abandonar, então, a idéia de que o federalismo tal qual concebido pelos constituintes de 1988 exprime uma busca pelo equilíbrio" (p. 70). Ao contrário, o Brasil funciona como um Estado Unitário, menos descentralizado que vários Estados autonômicos, a exemplo da Espanha e da Itália. Há, portanto, necessidade de várias reformas substanciais e, sobretudo, da construção de um novo pacto político que reestruture o sistema federativo brasileiro. Parece fundamental, na conclusão deste artigo, citar Ferreira de Melo (2005, p. 2) quando se refere ao federalismo brasileiro:

A centralização política, econômica e administrativa que ainda ocorre no Brasil, ao arrepio da matéria constitucional, é resultado de obscuras forças centrípetas que têm raízes longínquas no autoritarismo de nossas práticas coloniais e do período imperial e, mais recentes, mas não menos prejudiciais à construção democrática, no coronelismo da Primeira República e nas oligarquias geradoras de privilégios que marcaram todo século XX. Tudo isso somado ao despreparo de uma população desprovida de sustentação educacional para reagir ao desmedido controle governamental em suas vidas, que vem abortando suas utopias e sua liberdade, têm gerado, ainda hoje, condições psicossociais para a imposição de regras autoritárias produzidas nos laboratórios da alquimia política de Brasília, sob os olhares permissivos, quando não cúmplices, de um Parlamento cuja maioria se agarra às benesses do poder central, a este se submetendo.

A Democracia política brasileira necessita buscar o novo, com fundamento na ética do comportamento dos políticos. Aspira-se que o agir dos governantes seja planejado no sentido de realizar prioridades inspiradas na solução dos problemas emergenciais. Há necessidade de que o princípio da eficiência na economia fortaleça, com efetividade, o desenvolvimento sonhado, sem proteção de grupos, promovendo ações estratégicas em busca de uma Sociedade relativamente sem pobreza e de um Estado que supra as necessidades básicas das camadas populares, sem paternalismo mantenedor da ignorância e da miséria. É necessário sepultar a Democracia atrasada protegida por regras eleitorais que incentivam sucessivos mandatos repetitivos, que protegem sempre os mesmos donos do Estado. A busca do novo precisa sacudir o jeito ensebado, vetusto e moroso do ordenamento do judiciário brasileiro, promovendo a abertura de flexíveis regras de proteção das necessidades essenciais. Este momento de crise nacional é oportunidade propícia, não apenas para reflexão, mas, sobretudo, para efetivas reformas.

\section{REFERÊNCIAS}

A ERA DA CORRUPÇÃO. Veja, São Paulo, ano 27, n. 1, p. 80-93, 5 jan. 1994.

ABREU, Cesar Augusto Mimoso Ruiz. Sistema federativo brasileiro - degeneração e reestruturação. Florianópolis: Letras Contemporâneas Oficina Editorial, 2004.

ALMEIDA, Fernanda Dias de. Competências na Constituição de 1988. 2. ed. São Paulo: Atlas, 2000.

ARENDT, Hannah. A condição humana. Tradução Roberto Raposo. 10. ed. Rio de Janeiro: Forense, 2001. Título original: The Human Condition.

ARISTOTE. Éthique de Nicomaque. Paris: Librairie Garnier Frères, 1950.

ARISTÓTELES. Política. Tradução Therezinha Monteiro Deutsch Baby Abrão. São Paulo: Nova Cultural, 1999. (Coleção Os Pensadores).

ATIENZA, Manuel. Contribución a una Teoria de La legislación. Madrid: Cuadernos Civitas, 1997.

BARBOSA, Ruy. A questão social e política no Brasil. Disponível em: <www.casaruibarbosa.gov.br>. Acesso em: 3 out. $2009 a$.

. O Congresso e a Justiça no regime federal. Disponível em: <www.casaruibarbosa.gov.br>. Acesso em: 3 out. $2009 \mathrm{~b}$.

BULOS, Uadi Lammêgo. Constituição Federal Anotada. 4. ed. São Paulo: Saraiva, 2002.

CABO MARTIN, Carlos de. Sobre el Concepto de Ley. Madrid: Editorial Trotta, 2000.

CANTON, Cleide. Sinto vergonha de mim. Disponível em: <www.slideshere.net>. Acesso em: 2 out. 2009.

CÍCERO, Marco Túlio. Da República. Tradução Amador Cisneiros. São Paulo: Escala, 1995. (Coleção Os Pensadores).

CIMADON, Aristides. Autonomia dos Estados Federados e Direito Educacional. Florianópolis: Conceito; Joaçaba: Ed. Unoesc, 2007.

Considerações sobre Estado e Direito a partir das concepções de moral e de Justiça em Platão e Aristóteles. Revista Jurídica, Joaçaba, v. 4, n. 1, p. 9-30, 2003.

COSTA, Maurício Mesurini da. A Notícia. Joinville, quarta feira, p. 9, 23 set. 2009. AN Opinião.

COSTA, Nelson Nery; ALVES, Geraldo Magela. Constituição Federal anotada e explicada. 2. ed. Rio de Janeiro: Forense, 2003. 
DALLARI, Dalmo de Abreu. Elementos de Teoria Geral do Estado. 13. ed. São Paulo: Saraiva, 1987. . O Estado Federal. São Paulo: Ática, 1986.

DE PLÁCIDO E SILVA. Vocabulário jurídico. 10. ed. Rio de Janeiro: Forense, 1987.

DICIONÁRIO. Diccionário de la corrupción en Venezuela, vol. 1, 1959-1979, Caracas, 1980.

DINIZ, M. H. Dicionário jurídico. São Paulo: Saraiva, 1998. p. 407.

EFE, Agência. Brasil tem os piores índices de controle da corrupção nos últimos 10 anos. Disponível em: <http://www.bbc. co.uk/portuguese/reporterbbc/story/2007>. Acesso em: 29 set. 2009.

EL MAPA de la corrupción en los negocios latinoamericanos. Rev. América Economia, New York, año 4, n. 42, p. 9-20, ago. 1990. FERNANDES, Newton. A "corrupciocracia” brasileira e as formas utilizadas nas investigações criminais correlatas. Revista de Direito, São Paulo: Universidade Ibirapuera, v, 1, n. 3, p. 289-309, 2000.

FERREIRA DE MELO, Osvaldo. Tendências do federalismo no Brasil. Florianópolis: Lunardeli, 1989.

. Princípio federativo e a autonomia dos sistemas de ensino. Boletim Jurídico, ano 3, n. 132, p. 2, 2005.

FILIPIM, Eliane Salete; ROSSETO, Adriana Marques. Políticas públicas, federalismo e redes de articulação e desenvolvimento. Joaçaba: Ed. Unoesc, 2008. 151p. p. 121-133.

GARCIA, Alexandre. Comentário diário na Rádio Educativa FM. Joaçaba, 10 jul. 2017.

LAFER, Celso. O significado de República. Disponível em: <www.cpdoc.fgv.br/revista/arq>. Acesso em: 27 set. 2009.

LAMY, Marcelo. Concepção e evolução do Estado moderno. São Paulo: ESDC, 2009.

MARTINS, Cristiano Franco. Princípio federativo e mudança constitucional - limites e possibilidades na Constituição Brasileira de 1988. Rio de Janeiro: Lumen Juris, 2003.

MONTESQUIEU, Charles Louis de Secondat. Barão de la Brede e de. Do espírito das leis. Tradução Cristina Muracho. 2. ed. São Paulo: Martins Fontes, 2000. (Título original: Del L'esprit des Lois).

MORAIS, Carlos Blanco de. Democracia e consenso na decisão de legislar. Revista Brasileira de Direito Constitucional - RBDC, São Paulo, n. 3, jan./jun. 2004.

PASOLD, Cesar Luiz. A fundação social do Estado contemporâneo. 3. ed. Florianópolis: OAB-SC Editora e Coedição Diploma Legal, 2003.

PLATÃO. A República. Tradução Pietro Nassetti. São Paulo: Mertin Claret, 2001.

VALUCE, Ládmo. História do Brasil. São Paulo: Ed. do Brasil, 1973.

WOFF, Paul. Corrupção na América Latina. In: LÜDERSSEN, Klaus (Org.). Aufgeklärte Kriminalpolitik oder Kampf Gegen das Bose? Política criminal racional ou luta contra o mal. Baden-Baden: Nomos Verlagsgesselschaft, 1998. p. 413-432.

ZANCANARO, Antônio Frederico. A corrupção político-administrativa no Brasil. São Paulo: Acadêmica, 1994. 